\title{
COLLABORATIVE PROJECT BRIEF SCORECARD METHOD: EVALUATING PRODUCT DESIGN PROJECTS TO AID DESIGN EFFORT ESTIMATION
}

\author{
A. Holliman ${ }^{凶}$, A. Thomson and A. Hird \\ University of Strathclyde, United Kingdom \\ $\triangle$ alexander.holliman@strath.ac.uk
}

\begin{abstract}
Designers use their tacit knowledge to estimate project design effort needs, which can be enhanced through the understanding of the factors that most influence those needs. Evaluating and assessing project briefs against these factors can assist designers when planning their projects. The Collaborative Project Brief Scorecard (CPDS) Method identifies those factors and produces a scorecard for designers to evaluate project briefs based on these factors and allows for project comparisons, aids in past project recall and provides a focal point for collaborative reflection on design activities.
\end{abstract}

Keywords: design management, project management, product design, design effort, project scorecard

\section{Introduction}

Design effort is the key resource in product design projects. As a resource based on time, it cannot be replaced once used, making it a critical focus of product design project planning. Yet as an activity, design is an ill structured problem with incomplete, unspecific goals; no predetermined solution path; and need for integration of multiple knowledge domains. (Simon, 1977). This makes planning design projects and estimating design effort needs a critical challenge to be overcome. Understanding what influences design effort levels can provide key insight into required resource levels. Knowing which of these factors have the greatest influence and how they influence design effort levels would lead to improved forecasting and project planning.

This paper discusses the Collaborative Project Brief Scorecard (CPBS) Method, a proposed method for identifying design effort influential factors in product design, to produce a scorecard tool for evaluating new projects. The foundation of this approach is taken from the influential factor identification method proposed by Holliman et al. (2019). The method proposed in this paper will enable design teams to evaluate project briefs with a scorecard tool, which assigns a grade to each of the influential factors, allowing for comparisons between projects, both past and current. By creating scorecards for projects, designers and managers can readily identify similar projects, draw comparisons between said projects, aid recall on experiences with past projects and improve project planning. This is of particular value for product design agencies, organisations which specialise in the design and development of new products for other parties, businesses, etc. from a broad range of sectors, where no two projects are likely the same. 


\section{Background}

This section is in three parts; the first discusses the use of estimation in the planning process for design projects. The second briefly discusses the practice of considering any design effort level influencing factors as the sum of various elements, or the creation of composite factors based groupings of more specific factors. The third section discusses the practice of evaluating design projects, the approaches commonly used both specifically to design projects, and in project management in general.

\subsection{Estimating in design project planning}

One of the initial activities conducted when the planning of any project starts, is the estimation of time or cost (Association for Project Management, 2012; Mantel et al., 2011; Maylor, 2010; Pinto, 2010). Typically there are three approaches to estimating: Comparative, Parametric, and Bottom-up. Comparative (analogous) estimating bases estimates on historical data, making adjustments to past project information based on scope, complexity, etc. Parametric estimating uses a range of previouslydefined parameters that are used to measure a project. This evaluation is used to predict values in the current project. This requires a large body of past estimates of similar projects to work (Association for Project Management, 2012).

Designers using their experience and tacit knowledge when planning projects have proven to have valuable insight into project planning (Serrat et al., 2013). Yet, the more experienced the designers are, the harder it is for them to articulate specific knowledge (Clarkson and Hamilton, 2000). As design projects are typically characterised by uncertainty and complexity, designers rely on their experience and knowledge to manage project complexity (Crespo-Varela et al., 2012). Therefore stands to reason that any means to aid, or prompt, the recall of past projects with similar characteristics would be of significant benefit to designers during the planning process. Furthermore, understanding not only how each factor influences design effort levels, but how their influence changes over the course of a design project has significant value when planning. This value can also be applied to the consideration of new projects, developing quotations, planning, etc. design agencies already assess projects informally and formally. By developing a database of past project scores, a design agency can develop a corporate memory to enhance their project planning activities.

\subsection{Elements of influential factors in design effort levels}

There are several discussions of influential factors of design effort levels which suggest that there are contributing elements to each factor. Some studies offer a range of factors, where only some have elements, such as Bryson and Delbecq (1979) who reflects that the "contextual variables" (factors) of "Degree of value agreement" and "Technical Difficulty" can be sub-divided, as illustrated in Table 1.

Table 1. Contextual variables (factors) elements; adapted from Bryosn and Delbecq (1979)

\begin{tabular}{r|l} 
Contextual Variable (Factor) & Element \\
\hline Degree of Value Agreement & Awareness of problem \\
& Priority given to problem \\
Technical Difficulty & Intensity of concern \\
& $\begin{array}{l}\text { Comprehension of causation } \\
\text { Sophistication of technology }\end{array}$
\end{tabular}

Other studies go as far as to identify a set of factors with elements to generate a further "transitional" set of factors and elements, which all contribute towards product design time, such as those discussed by $\mathrm{Xu}$ and Yan (2006). In their paper, Xu \& Yan propose a Conceptual model of factors that influence design time, detailed in Figure 1, which takes the factors of "Product Characteristics", "Design Process", "Design Condition" and "Design Process"; each with their own set of elements and produces three further factors ("Product Complexity", "Information Process Capability" and "Motivation"). 


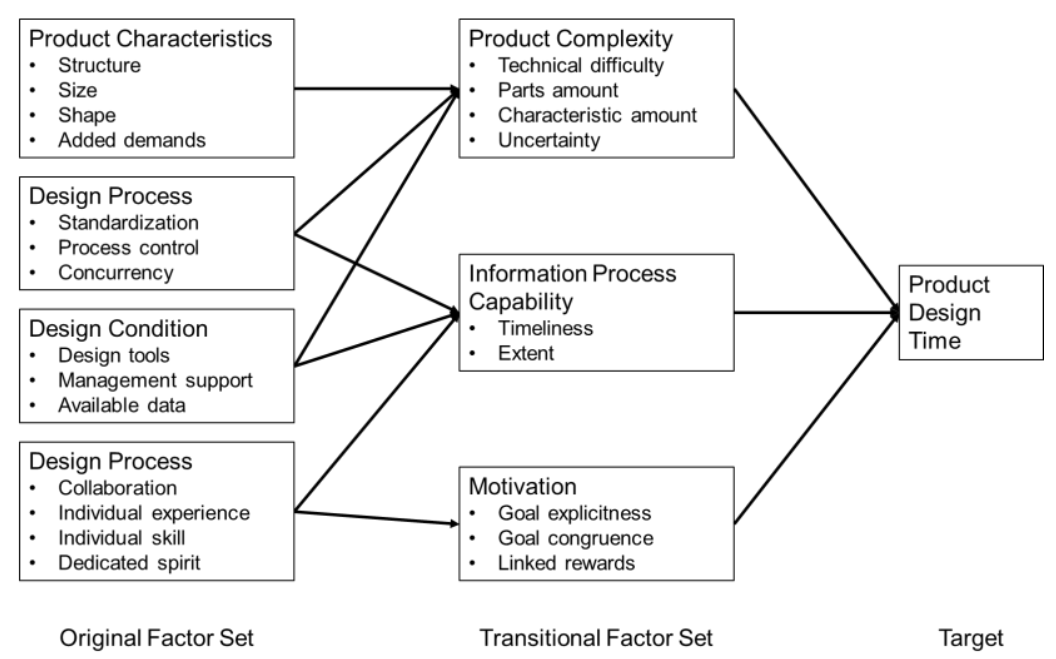

Figure 1. Conceptual model of factors that influence design time; adapted from Xu and Yan (2006)

\subsection{Evaluating design projects}

There are many facets to business practices that companies will need, or at least want, to evaluate. From suppliers and their supplies, to subcontractors and their costs. New stakeholders will be assessed and evaluated as and when they are required, and will then be assessed periodically to ensure suitability, determine performance, etc. Every company an agency works with will have their own approach, tools and processes to organisation, planning, etc. of their business. Agencies should too have their own approach, tools and processes to aid in the analysis of these companies, providing insight to the planning process (Wickham and Wilcock, 2012). Yet it is not just stakeholders that should be evaluated, but the design projects themselves.

There are many different evaluation processes and tools available and widely used in project management. These include processes like the Strength, Weaknesses, Opportunities and Threats (SWOT) and Political, Economic, Sociological, Technological, Legal and Environmental (PESTLE) analyses (Aguilar, 1967). These approaches can be conducted at any stage of a project (before, during, after, etc.) and provide lists of issues to be considered. These approaches are also versatile, as they can be used to investigate various aspects of a project.

There are also more detailed approaches where projects are evaluated against a set of criteria and given a numerical score, i.e. a scorecard, such as Kaplan \& Norton's Balanced Scorecard (1998). The Balanced Scorecard is a widely-used approach to the evaluation of projects, producing a series of objectives, each of which has their own set of measures, targets and initiatives. It takes a set of criteria to measure against and offers a management system with an emphasis on both financial measures, as well as those of customers, internal business processes, and learning and growth (Kaplan and Norton, 1992; Wickham and Wilcock, 2012). The Balanced Scorecard approach has been adopted and adapted in a host of different ways, dominating the literature on project management scoring, with use cases too broad and diverse to enumerate here. This approach has been used widely to improve processes, but is focused on monitoring performance against key performance indicators (KPIs), rather than as a categorisation and reflective tool for practitioners to use to help gain insight into the phenomena surrounding design project planning. Furthermore, these approaches typically are reflective, where practitioners of the methods review project performance after the fact, rather than assess the project from the outset. It is clear that the use of scorecards for business issue evaluations has widespread use, a vernacular that a broad range of businesses will be familiar with, therefore a tool which uses a similar approach can capitalise on this established comprehension.

\section{Collaborative project brief scorecard (CPBS) method}

The Collaborative Project Brief Scorecard (CPBS) Method is a simple, yet valuable method for developing a scorecard to evaluate product design projects. CPBS scorecards are able aid designers 
and design team managers to effectively collect valuable data from their projects, to aid in the planning of future projects by producing a scheme by which all projects can be evaluated.

\subsection{Collaborative project brief scorecard (CPBS) method background}

This paper presents the CPBS method, which builds upon the design effort influencing factor identification method proposed by Holliman et al. (2019), which in-turn has developed from the research of Hird (2012). This method captured the tacit knowledge of design teams to identify and model the most influential factors of design effort in product design projects. The author's method proposed a six-step process (described by the left column of Figure 2) similar to a traditional design of experiments approach (Fisher, 1949), to produce a series of hypothetical product design projects based on an experimental design, where the factors are the design effort influencing factors.

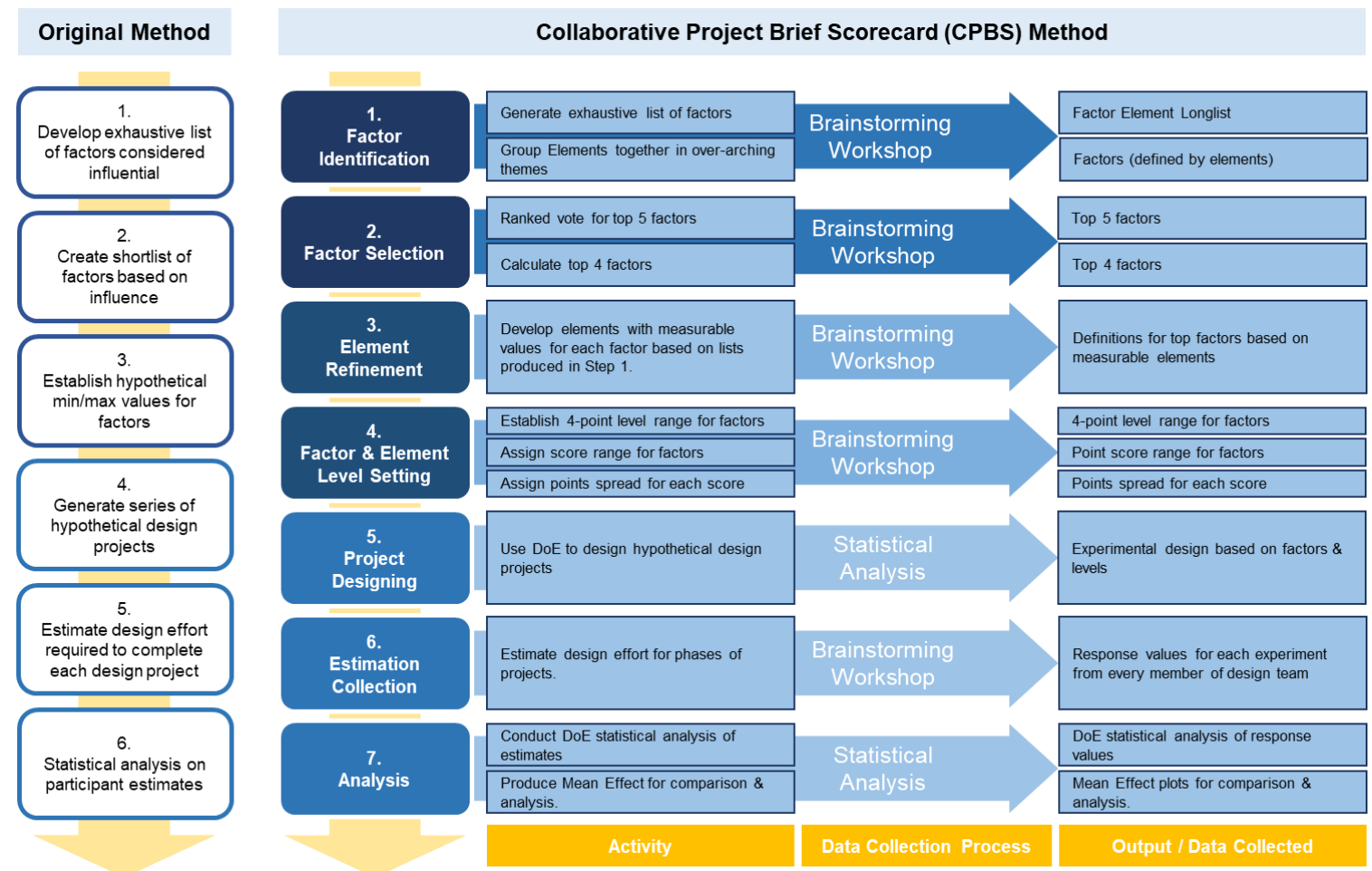

Figure 2. Collaborative project brief scorecard (CPBS) method

There are three main differences between the method proposed by Holliman et al. (2019) and the CPBS method:

1. The CPBS method includes the development of a series of elements to aid in the definition and quantification of each factor

2. The main purpose of the CPBS method is to utilise the data not currently used in the original method, to produce a bespoke scorecard that a design team can use to evaluate all future projects.

3. The purpose of the CPBS scorecard is to record the evaluation generated for each project to enable reflection and recall of past project experiences, aiding in the development of best practices and other strategies to improve project execution.

\subsection{Collaborative project brief scorecard (CPBS) method}

The CPBS Method is a seven-step approach for teams to work collaboratively to produce a product design project-evaluating scorecard based on the most influential factors of design effort for said projects. Shown in the second column of Figure 2, the seven steps are: Factor Identification, Factor Selection, Element Refinement, Factor and Element Level Setting, Project Designing, Estimation Collection, and Analysis. 


\subsubsection{Factor identification}

In a workshop environment, the design team collaboratively generate an exhaustive list of all possible issues (elements) which they perceive could influence design effort levels and group them together into over-arching themes or commonalities, to create a list of factors. It is key that design teams select factors based on their own perceptions, so that they have clear understanding of what each factor is. Doing so in a brainstorming workshop, allows for discussion and sharing that understanding if needed.

\subsubsection{Factor selection}

Within the same workshop, participants will identify the top four factors they believe to have greatest influence over design effort levels. This will be done by way of private vote.

\subsubsection{Element refinement}

Participants select the elements (from the originating collection) that are measurable. This is key to ensuring that the scorecard has no abstract concepts that design teams will have to interpret before use. Additionally, by defining factors by their levels, the CPBS method ensures that the factors are broad, while the elements can be specific, enabling projects with differing elements, to have similar overall scores.

\subsubsection{Factor and element level setting}

Participants collaboratively define four levels for every measurable element of each factor (a maximum, a minimum and two mid-values; each clearly identifiable). This is similar to that used by Hubka and Eder (1988) in their method for measuring product complexity. These levels are given a point score (1 to 4 based on likely influence over design effort levels). Once assigned, the minimum and maximum scores possible are calculated and a distribution of total scores for each factor can be calculated, with a factor score associated with each.

\subsubsection{Project designing}

During Project Designing, the CPBS method uses statistical analysis (typically though software such as MS Excel or Minitab 17.0) to produce a half factor experimental design (based on the design of experiments approach (Fisher, 1949)), using the factors and levels previously defined, and the steps of the design teams' own design process produce hypothetical product design projects.

\subsubsection{Estimation collection}

Estimation Collection sees the design team individually estimate the design effort levels for each phase of each hypothetical project created in the previous step.

\subsubsection{Analysis}

Response vales (design effort estimates) of each member of the design team are analysed using analysis software (MS Excel, Minitab 17.0, etc.) to identify the level of perceived influence each factor has over design effort levels for product design projects. Mean Effect plots are generated, illustrating the behaviour of the factors at every stage of the design project. A detailed discussion on the additional advantages to this analysis is covered by Holliman et al. (2019).

\subsection{CPBS method summary}

The CPBS Method takes the process developed by Holliman et al. (2019) and produces a product design project scorecard based on the factors which have the greatest influence over design effort levels. By creating this scorecard, not only do design teams benefit from the insight generated by the originating method, but also create a valuable tool which can be used for all future projects, enabling the direct comparison between design projects and opportunities to gain further insight into the design space. Furthermore, by involving the whole design team in the development of the scorecard, the team as a whole develop a greater knowledge of the tool itself and improved faith in the scorecard's output. 


\section{Case study example}

\subsection{Case study introduction}

This section presents data taken from a case study which illustrates the application of the CPBS method in industry. The scorecard was developed and influential factors were identified for a UK-based product design agency specialising in high-end bespoke interior architectural pieces, furniture and equipment transportation solutions for commercial and retail spaces, as well as for private, residential clients. Throughout this study, this agency will be referred to as Product Design Agency A (PDAA). At the time of the study, PDAA employed four design team members with various degrees of experience, including a head designer trained in architecture, experienced carpenters and workshop manager.

This case study will describe the development of a complete scorecard using the CPBS method, providing the details of one specific factor, in this case the factor of Product Complexity.

\subsection{Case study findings \& discussion}

\subsubsection{Factor identification}

During a brainstorming workshop, participants collaboratively agreed on a list of all possible influences for design effort levels, initially by project phase, then grouping these into lists of common themes, creating factors. For Product Complexity, these elements are stated in Table 2. Considering just these elements and their definitions (which were provided by the participants), it is clear that a number of these elements consider the same, or similar issue. During a series of individual semi-structured interviews after the case study, participants stated that this discussion was valuable to the team, as it provided an opportunity to raise concerns relating to the project work in an informal setting. This provides a clear advantage for teams where communication may be restricted due to the culture within the business.

Table 2. Example of contributing elements to a factor for "Product Complexity" factor

\begin{tabular}{|c|c|}
\hline Elements & Definition \\
\hline $\begin{array}{r}\text { Future } \\
\text { Maintenance? }\end{array}$ & $\begin{array}{l}\text { How much maintenance would be expected of the agency after the product has been } \\
\text { delivered }\end{array}$ \\
\hline Potential Misuse & The likeliness of the product being used incorrectly \\
\hline Life Span & The expected time the product would remain functional \\
\hline Material Type & The types and quantities of materials needed for the final product \\
\hline Durability & How hard wearing the product is be expected to be \\
\hline Tricky Materials & Do the materials specified need special equipment or skill to use? \\
\hline $\begin{array}{r}\text { Does it have } \\
\text { wheels? }\end{array}$ & A summary term for portability and likelihood that it would be moved during its use \\
\hline $\begin{array}{r}\text { Material } \\
\text { Restrictions }\end{array}$ & Are there limits to the uses of the material, either functionally or otherwise? \\
\hline Scale & What is the anticipated size of the final product? \\
\hline
\end{tabular}

\subsubsection{Factor selection}

Within the same workshop, the PDAA design team privately voted for Product Complexity as one of the top four factors they believed to have greatest influence over design effort levels.

\subsubsection{Element refinement}

The PDAA design team selected the elements from the originating collection (shown in Table 2) that are measurable to refine the elements. Figure 3 shows the refined elements of Product Complexity as perceived by PDAA. In semi-structured interviews after the case study, participants reflected on the benefits of this refinement process, stating that this activity helped contextualise the factors more clearly. This was of particular benefit when working towards the Estimation Collection phase, discussed later in this paper. 


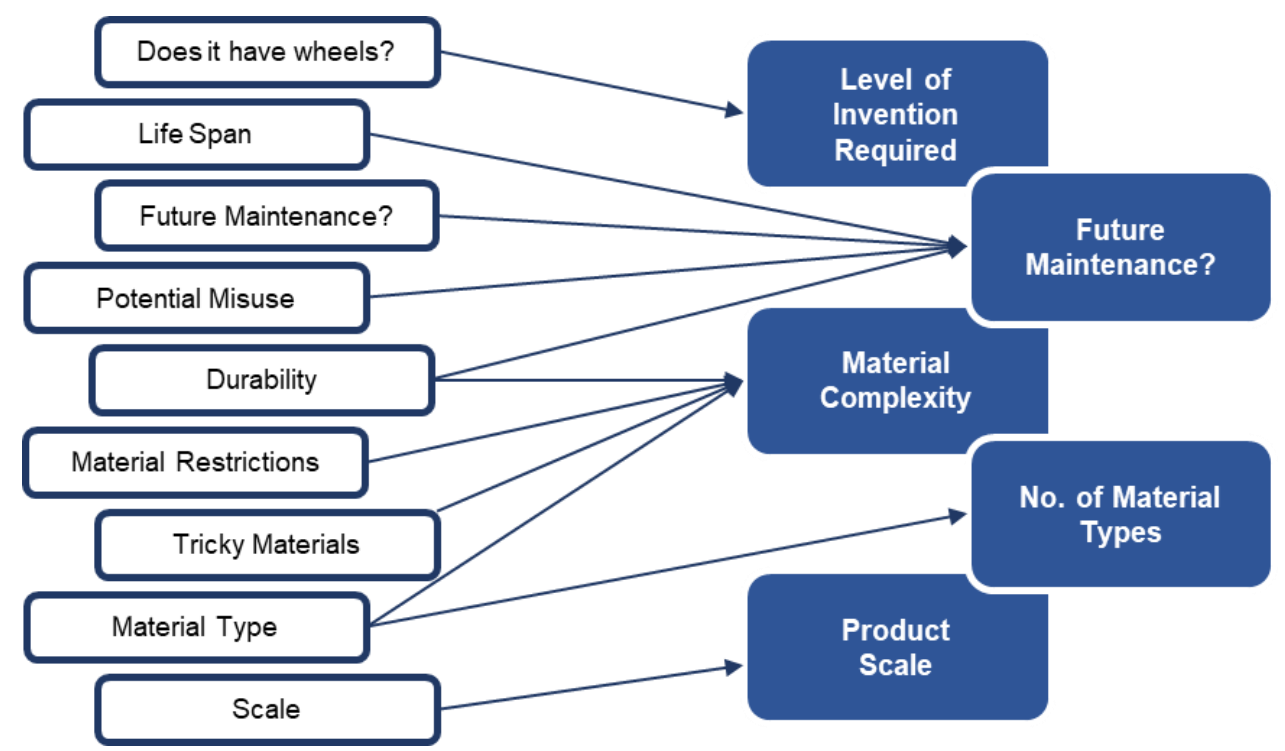

Figure 3. Product complexity elements for PDAA

\subsubsection{Factor and element level setting}

The PDAA design team defined four levels for each element and factor collaboratively, shown in Figure 4. These levels were given a point score and point spread (shown at the bottom of Figure 4). Creating this range of levels for the elements of each factor provided the key details needed to produce PDAA's design project scorecard. An example of the Product Complexity factor section of the project scorecard is shown in Figure 5 showing the factor scoring for a particular project.



Figure 4. Product complexity factor elements \& levels for PDAA

\begin{tabular}{|c|c|c|c|c|c|c|c|c|}
\hline \multirow{2}{*}{ Factor } & & \multirow{2}{*}{ Element } & \multicolumn{4}{|c|}{ Element Levels } & \multirow{2}{*}{ Total } & \multirow{2}{*}{$\begin{array}{l}\text { Factor } \\
\text { Score }\end{array}$} \\
\hline & & & 1 & 2 & 3 & 4 & & \\
\hline \multirow{5}{*}{$\begin{array}{l}\text { Product } \\
\text { Complexity }\end{array}$} & 1 & Level of Invention Required & & $x$ & & & \multirow{5}{*}{13} & \multirow{5}{*}{3} \\
\hline & 2 & Future Maintenance & & & $x$ & & & \\
\hline & 3 & Material Complexity & & & $x$ & & & \\
\hline & 4 & Product Scale & & & $x$ & & & \\
\hline & 5 & No. of Material Types & & $\mathrm{x}$ & & & & \\
\hline
\end{tabular}

Figure 5. Product complexity factor elements \& levels for PDAA 


\subsubsection{Project designing}

The remaining three steps of this process enabled PDAA's design teams to gain a greater understanding of how each of the factors influence the design effort levels of their projects. During Project Designing, the CPBS method uses statistical analysis (typically though software such as MS Excel or Minitab 17.0) to produce a half factor experimental design (based on the design of experiments approach (Fisher, 1949)), using the factors, and the maximum and minimum levels previously defined, and the steps of the design teams' own design process produce hypothetical product design projects.

\subsubsection{Estimation collection}

PDAA's design team took less than one hour to individually estimate the duration of each of the hypothetical projects. These estimates were considered to be the response values for the experimental design and were measured in days.

\subsubsection{Analysis}

Response vales (design effort estimates) of each member of the design team are analysed using analysis software (MS Excel, Minitab 17.0, etc.) to identify the level of perceived influence each factor has over design effort levels for product design projects. Mean Effect plots are generated, illustrating the behaviour of the factors at every stage of the design project. An example of the Mean Effect Plots is shown in Figure 6.

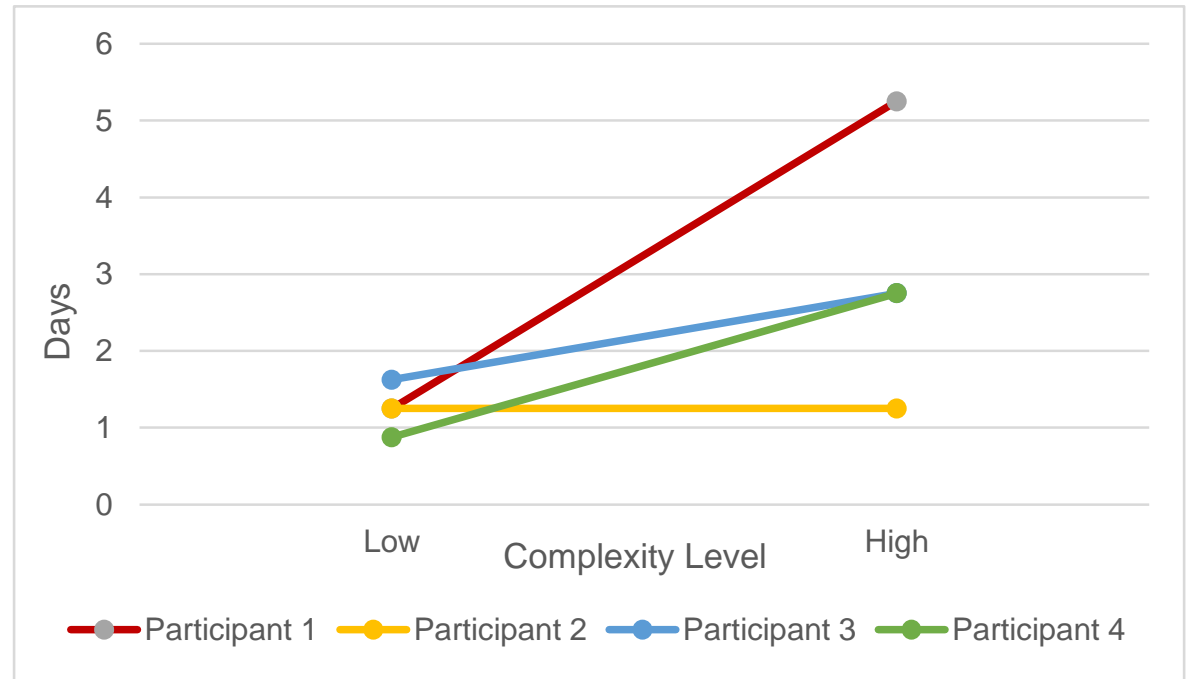

Figure 6. Mean effect plot for product complexity during prototyping phase

\section{Scorecard use}

The development of this scorecard has a number of benefits, both in the identification and assessment of influential factors and in the assessment of future projects.

\subsection{Factor identification}

During the estimation phase of the CPBS Method, participants can use the scorecard as an aid when estimating design effort. By using tables similar to those shown in Table 3, designers have a clearer understanding of factor characteristics at the levels described in the experimental designs generated in Step 4 of the Evaluation Method.

\subsection{Project assessment}

Although the insight offered by Evaluation Method enables designers and managers to assess future projects to aid in the overall understanding, this understanding is has limited clarity due to the possible 
abstract nature of the factors identified. With the introduction of a scorecard in the CPBS Method, creating listed and quantified elements, project briefs can be evaluated in greater detail. This improved detail enables project planners to not only make improved, informed estimates of design effort based on generated scores, but also identify potential additional project resources required based on the levels of each element.

\subsection{Project comparison}

Using the scorecard reflectively to evaluate past projects can provide significant additional benefits to designers and managers. By recording the scores of past project, comparing them to the evaluation of future projects, designers and mangers are able to make comparisons and make further informed decisions on design effort estimation and broader project planning decision making.

The CPBS Method Scorecard offers two levels of comparison between projects. At a higher level, projects can be evaluated by the overall scores for each factor. However, as various combinations of element levels can result in the same score, comparing projects based on the element levels provides more specific comparisons with the potential for greater value. Furthermore, by comparing at this granular level, projects that have different factor scores, can still be compared for the same element scores.

Furthermore, this activity could be regularly conducted collaboratively with the entire design team to maximise the utility of the scorecard, by providing a focal point for conversation about the performance of such projects. These discussions could further be enhanced when the scorecard is used in conjunction with the Mean Effect plots.

\section{Future work}

In order to determine the complete functionality of the CPBS Method, a complete implementation with a number of product or industrial design agencies, multi-discipline design teams or similar should be performed. Through such experimentation it will be possible to better understand all the possible benefits that CPBS Method can offer to the design community.

\subsection{Specific benefit analysis}

Further studies should be conducted using CPBS Method to measure the specific benefits that reflective past project scoring could have on future project planning. Past projects could be scored using the scorecard and then comparisons could be made against planning made with and without the identification of similarly scored past projects.

\subsection{Optimising the design space}

In their discussion, Holliman et al. (2019) suggest that, as optimisation is the most common use of the Design of Experiments approach, it would be possible to optimise the design space for design team. This could be accomplished by reducing the negative influence of some factors and increasing the positive impact of others. With the identification of specific, measurable elements to factors brought with CPBS Method, it would be possible to focus and target these improvements, enabling such improvements to be made more easily and appropriately. This improved level of focus would enable more specific and therefore effective changes to be made.

\subsection{Recommendation engine}

Considering the scorecard as a digital tool, then it would be possible to program recommendations for projects if certain criteria were met. This may be suggesting an increase of project estimate by a percentage, adding a buffer for potential project set-backs; or taking the product complexity factor used in the case study, the inclusion of additional development phases based on an evaluation where both the "level of invention" and "material complexity" elements are set to their highest level. 


\section{Conclusion}

The Collaborative Project Brief Scorecard (CPBS) Method proposed in this paper produces an evaluation tool taking the well-established and adopted form of a scorecard. Identifying the most influential factors of design effort levels in product design, it assists design agencies to develop a corporate memory, a resource to aid in the planning and estimation of design activities and projects. If fully and properly utilised, the CPBS method scorecard would allow design teams to effectively assess projects based on a set of established criteria, provide a design team with a focal point for discussions and reflections of their own design practice, generate datum to compare future projects with past offering learning opportunities.

\section{References}

Aguilar, F.J. (1967), Scanning the Business Environment, Macmillan, London.

Association for Project Management (2012), APM Body of Knowledge, 6th ed., Association for Project Management, Princes Risborough, Buckinghamshire.

Bryson, J.M. and Delbecq, A.L. (1979), "A Contingent Approach to Strategy and Tactics in Project Planning", Journal of the American Planning Association, Routledge, Vol. 45 No. 2, pp. 167-179.

Clarkson, P.J. and Hamilton, J.R. (2000), "'Signposting', A Parameter-driven Task-based Model of the Design Process", Research in Engineering Design, Vol. 12 No. 1, pp. 18-38.

Crespo-Varela, J.R. et al. (2012), “An Analysis of Complexity Measures for Product Design and Development.

Fisher, R.A. (1949), The Design of Experiments, 5th ed, Oliver and Boyd, Edinburgh.

Hird, A. (2012), A Systems Approach to Resource Planning in New Product Development, edited by University of Strathclyde. Dept. of Design, M. and E.M., Thesis [Eng. D] -- University of Strathclyde, 2012.

Holliman, A. et al. (2019), "A Matter of Factor: A Proposed Method for Identifying Factors that Influence Design Effort Levels in Product Design", Proceedings of the Design Society: International Conference on Engineering Design, Cambridge University Press, Vol. 1 No. 1, pp. 1025-1034.

Hubka, V. and Eder, W.E. (1988), Theory of Technical Systems, Springer Berlin Heidelberg, Berlin, Heidelberg, available at: https://doi.org/10.1007/978-3-642-52121-8.

Kaplan, R.S. and Norton, D.P. (1992), "The balanced scorecard-measures that drive performance", Harvard Business Review, Harvard Business School, United States, Vol. 70 No. 1, pp. 71-79.

Kaplan, R.S. and Norton, D.P. (1998), "Using the Balanced Scorecard as a Strategic Management System", Harvard Business Review on Measuring Corporate Performance, Harvard Business School Press, Boston, pp. 183-212.

Mantel, S.J. et al. (2011), Project Management in Practice, 4th, John Wiley \& Sons (Asia) Pte Ltd., Hoboken, New Jersey.

Maylor, H. (2010), Project Management, 4th, Pearson Education Ltd., Edinburgh Gate, Harlow.

Pinto, J.K. (2010), Project Management: Achieving Competitive Advantage, 2nd, Pearson Education Inc., Upper Saddle River, New Jersey.

Serrat, J., Lumbreras, F. and López, A.M. (2013), "Cost estimation of custom hoses from STL files and CAD drawings", Computers in Industry, Vol. 64 No. 3, pp. 299-309.

Simon, H.A. (1977), "The Structure of Ill-Structured Problems BT - Models of Discovery: And Other Topics in the Methods of Science", in Simon, H.A. (Ed.), Springer Netherlands, Dordrecht, pp. 304-325.

Wickham, L. and Wilcock, J. (2012), Management Consulting: Delivering and Effective Project, 4th ed, Pearson Education Ltd., Harlow.

$\mathrm{Xu}$, D. and Yan, H.-S. (2006), "An intelligent estimation method for product design time", The International Journal of Advanced Manufacturing Technology, Vol. 30 No. 7, pp. 601-613. 